\title{
Creep behavior of ultra pure ferrite stainless steel 409M
}

\author{
YING Cai-hong ${ }^{1,2, a^{*}}$, LIU Tian-long ${ }^{1, b}$, CHEN Li-jia ${ }^{1, c}$ and GUO Lian-quan ${ }^{2, d}$
}

1 School of Materials Science and Engineering, Shenyang University of Technology,

Shenyang 110870, China

\author{
2 School of Science, Shenyang University of Technology, Shenyang 110870, China \\ arainbow-anna@163.com, ${ }^{b}$ Itl_0508@hotmail.com, ${ }^{c}$ chenlj-sut@163.com, ${ }^{d}$ guo_lq@163.com
}

Keywords: ultra-purified ferrite stainless steel; creep; rupture time; stress exponent; dislocation glide:transgranular ductile fracture.

Abstract. The creep tests have been conducted for ultra pure ferrite stainless steel $409 \mathrm{M}$ at $650^{\circ} \mathrm{C}$ and the applied stress ranging from $60 \mathrm{MPa}$ to $80 \mathrm{MPa}$. The creep deformations and rupture behaviors have been investigated. The results show that a brief primary creep stage is characterized under the condition of test. A larger applied stress caused a higher steady state creep rate and a shorter rupture time at $650^{\circ} \mathrm{C}$. The steady-state creep rate can be described by creep constitutive equation with the creep stress exponent $n$ of 2.34 , which shows a creep mechanism involving grain boundary sliding. The creep rupture data show an excellent agreement with the Monkman-Grant relationship. The fracture pattern belongs to transgranular ductile fracture.

\section{Introduction}

Ferrite stainless steel is an economical stainless steel due to little or no expensive nickel. In comparison with austenitic stainless steel, it is characterized by less linear expansion coefficient, higher strength at elevated temperature, superior thermal fatigue resistance and higher resistance to chloride stress corrosion cracking and cyclic oxidation. Thus, ferrite stainless steel is widely used in the automotive exhaust systems [1-5]. However, traditional ferrite stainless steel has some disadvantages, such as the poor formability and weldability, sensitive to intergranular corrosion. With the continuous development of iron and steel smelting technology, ultra pure ferrite stainless steels with better formability, weldability and corrosion resistance have been developed through reducing the content of $\mathrm{C}$ and $\mathrm{N}$ and optimizing alloying elements such as $\mathrm{Nb}$, Ti and $\mathrm{Mo}[6,7]$. Notably, $\mathrm{Nb}$ and Ti are strong forming elements of carbide and nitride, which can react with $\mathrm{C}$ and $\mathrm{N}$ and form the MX-type intermetallic, avoid the precipitations of chromium carbonitrides that have disadvantageous effects on the intergranular corrosion [8-11]. Wang et al. [12] reported that for the $12 \% \mathrm{Cr}$ ferrite stainless steel, $\mathrm{Ti}$ and $\mathrm{Nb}$ dual stabilization could eliminate or alleviate the intergranular corrosion generally associated with the precipitation of chromium carbides, nitrides and carbonitrides at the grain boundaries. Froitzheim et al. [13] found that the addition of $1 \% \mathrm{Nb}$ to the high-Cr ferrite steels led to an improvement of oxidation resistance. Further creep and thermal tensile strength were increased due to the precipitation of Laves phases when $\mathrm{Si}$ and $\mathrm{Nb}$ with suitable amount were added together. Actually, Mo is an excellent phase stabilization element. Liu et al. [14] researched the fatigue behavior of $15 \mathrm{CrNbTi}$ ferrite stainless steel and reported that Mo element could suppress the formation of coarsened $\mathrm{Fe}_{3} \mathrm{Nb}_{3} \mathrm{C}$ precipitate and resulted in the enhancement in fatigue resistance.

Many studies have been performed on the aspects of microstructures and mechanical properties of ferrite stainless steel $[15,16]$. However, there is little work focuses on the creep deformation behavior of ferrite stainless steel in the literature [17]. As a critical factor causing the damage, the creep behavior should be paid more attention. In the present study, the creep behavior of 409M ultra pure ferrite stainless steel used in the automotive exhaust systems were investigated through performing the constant load tensile creep test at different applied stresses and $650^{\circ} \mathrm{C}$ in order to determine its creep mechanism and fracture mode. 


\section{Experimental Procedures}

The commercially available 409M ultra pure ferrite stainless steel used in the current study was supplied in the form of plates with a thickness of $1.7 \mathrm{~mm}$. The chemical composition of 409M is shown in Table 1. The creep specimens are machined from as-received steel plate and geometry of the specimen is shown in Fig.1. The gauge length of specimen is $16 \mathrm{~mm}$. The yield strength and ultimate tensile strengths of $409 \mathrm{M}$ ferrite stainless steel at $650^{\circ} \mathrm{C}$ are $117 \mathrm{MPa}$ and $226 \mathrm{MPa}$, respectively.

Table 1 Chemical composition of 409M [wt\%]

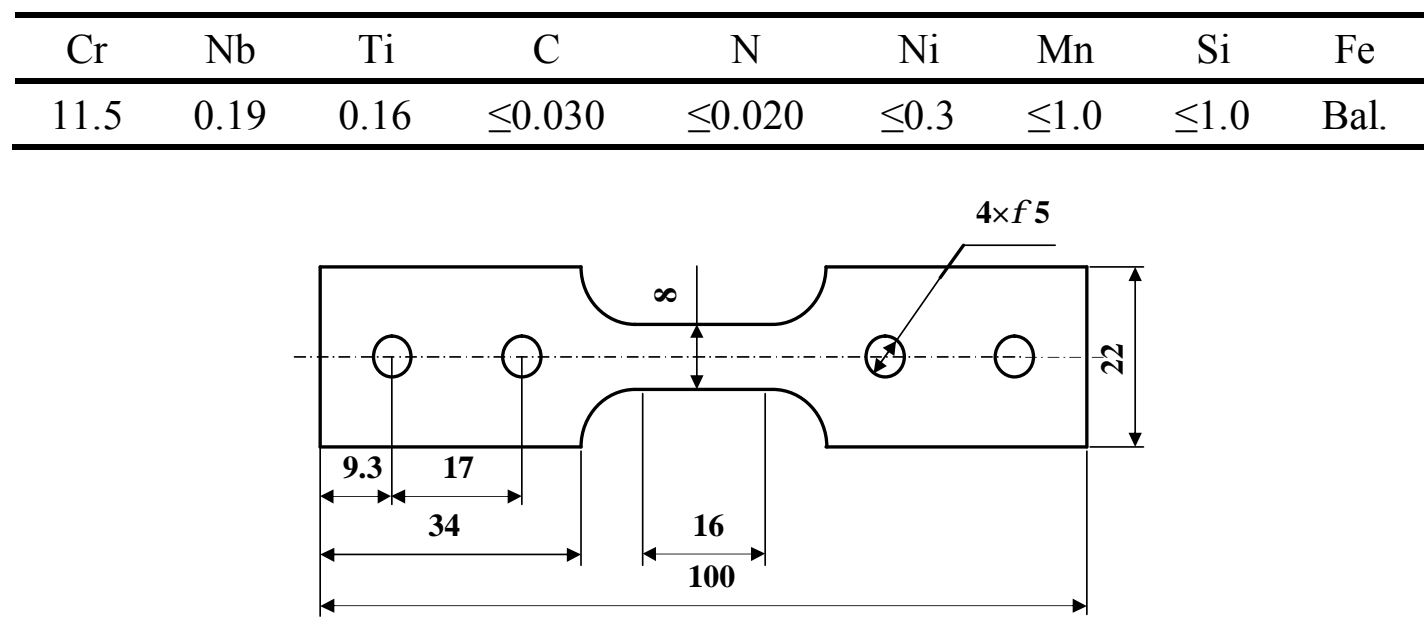

Fig. 1 Geometry of creep specimen (unit: $\mathbf{m m}$ )

The constant load tensile creep tests for the 409M steel were performed on GWT304 creep testing machine at $650^{\circ} \mathrm{C}$ and in laboratory environment. The applied stresses are $60 \mathrm{MPa}, 70 \mathrm{MPa}$ and $80 \mathrm{MPa}$, respectively. All creep tests were performed up to final creep fracture. The fracture surfaces were cleaned with using the ultrasonic wave cleaner, and the micrographs of fracture surfaces were observed with S-3400N scanning electron microscope (SEM) in order to determine the creep fracture mode of the steel.

\section{Results and Discussion}

Creep Behavior. Fig. 2 illustrates the typical creep strain curves for the $409 \mathrm{M}$ ferrite stainless steel at $650^{\circ}$ Cand different applied stresses. Correspondingly, the variation curves of creep rate with creep time are showed in Fig. 3. As shown in Fig. 2 and 3, all creep curves include three stages, namely primary stage, steady-state stage and tertiary stage. The primary stage of all creep curves is very brief and then the creep rate decreases rapidly. This means that the strain hardening effect gets rapidly recovered after the load is applied. Subsequently, the creep reaches the steady-state stage. The time to the creep rupture is dominated by the creep deformation in both secondary and tertiary stages. A larger applied stress caused a higher steady-state creep rate and a shorter rupture time at $650^{\circ} \mathrm{C}$. When the applied stress is $60 \mathrm{MPa}$, the steady-state creep rate is $6.23 \times 10^{-4} \mathrm{~h}^{-1}$, the specimen ruptures after $44 \mathrm{~h}$. With increasing the stress from $60 \mathrm{MPa}$ to $70 \mathrm{MPa}$ and $80 \mathrm{MPa}$, the steady-state creep rate increases to $9.07 \times 10^{-4} \mathrm{~h}^{-1}$ and $1.22 \times 10^{-3} \mathrm{~h}^{-1}$, respectively. However, the time to creep rupture reduces to $26 \mathrm{~h}$ and 20h. It implies that the 409M ferrite stainless steel has the larger stress sensitivity.

Creep Mechanism. When the creep reaches the steady-state stage, the steady-state creep rate \&\& is determined by both temperature $T$ and applied stress $\sigma$. For most materials, the functional relation among \&s $\sigma$ and $T$ follows the Norton's law given as below. 


$$
\&_{s \mathrm{~s}}=A \sigma^{n} \exp \left(-\frac{Q}{R T}\right)
$$

Where $A$ is the constant related to the material properties, $n$ is the stress exponent, $Q$ is the apparent activation energy, and $R$ is the universal gas constant. The stress exponent $n$ can be determined from the slope on the plot of $\lg \&_{s \mathrm{~s}}$ versus $\lg \sigma$ at the given temperature. Fig. 4 shows the relationship between the steady-state creep rate and applied stress for $409 \mathrm{M}$ at $650^{\circ} \mathrm{C}$. In this study, the value of $n$ is 2.34 , which indicates a creep mechanism of grain boundary sliding.

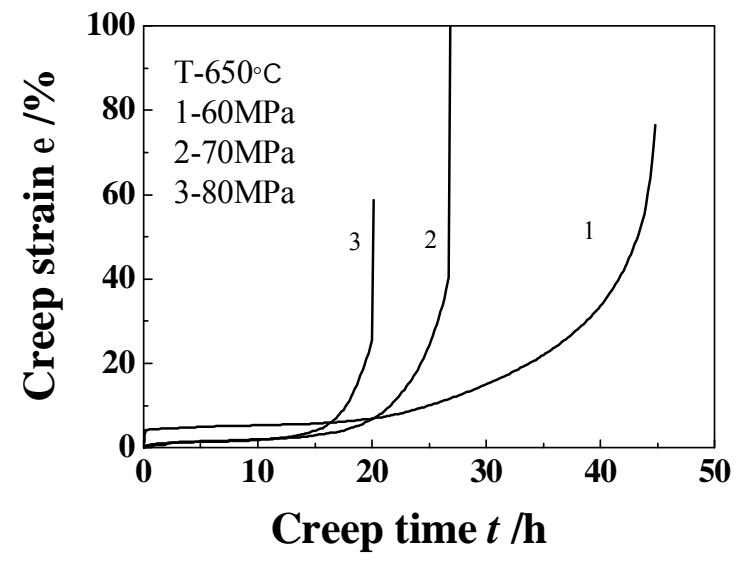

Fig. 2 Typical creep curves of $409 \mathrm{M}$ at $650^{\circ} \mathrm{C}$

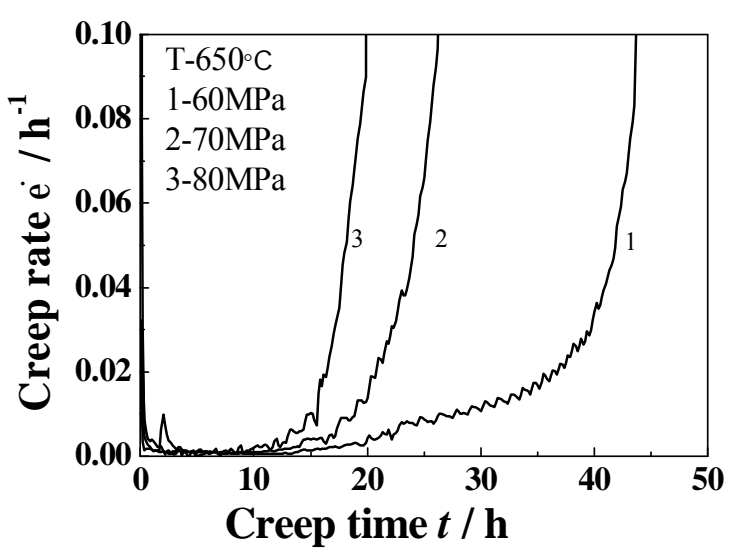

Fig. 3 Creep rate curves of $409 \mathrm{M}$ at $650^{\circ} \mathrm{C}$

In the study of creep, the value of stress exponent can be used to indicate the creep mechanism[18]. Generally, for metal materials, a value of $n$ with 1 and 2 represents the diffusional creep and creep mechanism controlled by grain boundary sliding, respectively. A value of $n$ in the range of 3 to 8 represents a dislocation type of creep mechanism.

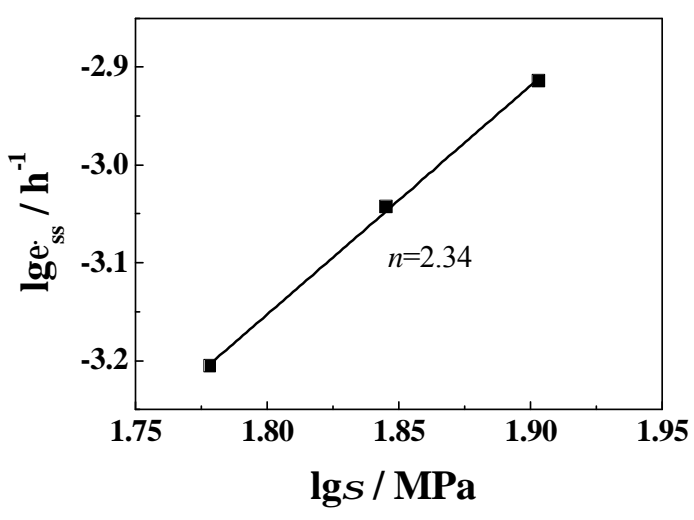

Fig. 4 Relation between steady state rate and applied stress for $409 \mathrm{M}$ at $650^{\circ} \mathrm{C}$

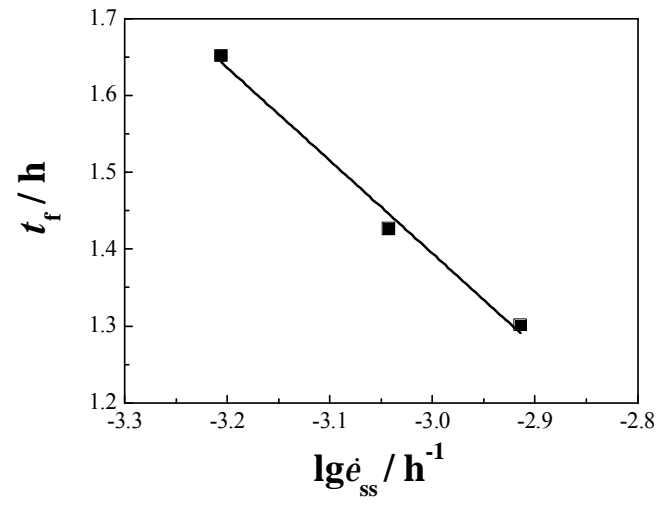

Fig. 5 Monkman-Grant relation for $409 \mathrm{M}$ at $650^{\circ} \mathrm{C}$

Time to Creep Rupture. The Monkman-Grant relation is a common method estimating the time to the long-term creep rupture of material and can be described as follows.

$$
\&_{\mathrm{ss}}^{n} \cdot t_{\mathrm{f}}=C_{\mathrm{MG}}
$$

where $\&_{\mathrm{ss}}$ is the steady-state creep rate, $t_{\mathrm{f}}$ is the time to creep rupture, and $C_{\mathrm{MG}}$ is the Monkman-Grant constant which depends on the material and temperature. The Monkman-Grant relation for the 409M steel at $650^{\circ} \mathrm{C}$ is showed in Fig. 5. As a consequence, the Monkman-Grant relation can be expressed as follows. 


$$
\&_{\mathrm{s}}^{21} \cdot t_{\mathrm{f}}=5.9 \times 10^{-3}, \quad r^{2}=0.98
$$

where $r^{2}$ is the correlation coefficient for the fitted curve. The Monkman-Grant ductility $\&_{s s} t_{\mathrm{f}}[19]$ that is equal to $C_{\mathrm{MG}}$ with $m \approx 1$ can be used to estimate the contribution of secondary creep strain to total strain. The smaller value of $\&_{\mathrm{ss}} t_{\mathrm{f}}$ for the $409 \mathrm{M}$ steel shows that the contribution of secondary creep strain is limited and the tertiary creep stage dominates the total creep strain.

In addition to the Monkman-Grant relation, the relation between the time to rupture $t_{\mathrm{f}}$ and applied stress $\sigma$ for the $409 \mathrm{M}$ steel at $650^{\circ} \mathrm{C}$ can be also correlated by a simple power law, as shown in Fig. 6 . The fitted equation and correlation coefficient are given as follows.

$$
\lg t_{\mathrm{f}}+2.81 \lg \sigma=6.64, \quad r^{2}=0.97
$$

The higher value of $r^{2}$ indicates that the time to rupture can be predicted by the formula (4).

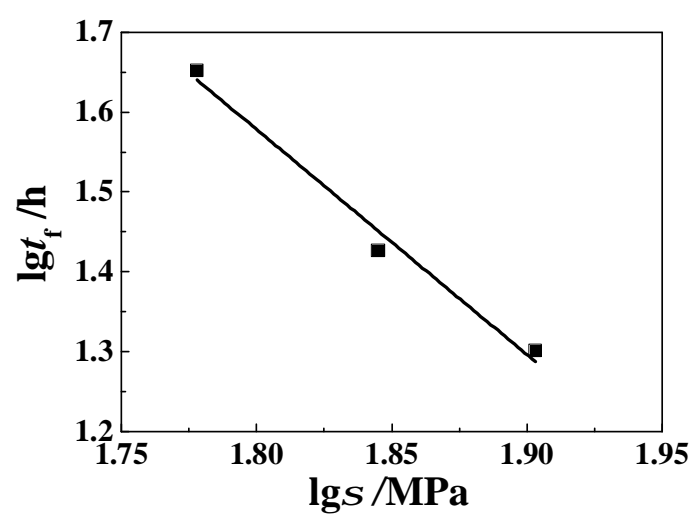

Fig. 6 Relation between the time to rupture and the applied stress of $409 \mathrm{M}$ at $650^{\circ} \mathrm{C}$

Fig. 7 shows the typical SEM micrographs of creep fracture surface for the $409 \mathrm{M}$ steel at $650^{\circ} \mathrm{Cand}$ $60 \mathrm{MPa}$. The creep fracture mode of the $409 \mathrm{M}$ steel is transgranular ductile fracture. Fig. 7(a) shows a greater extent of reduction of cross-sectional area. It means that the necking occurs before the creep rupture. And many big dimples with second-phase particles are seen in Fig. 7(b).
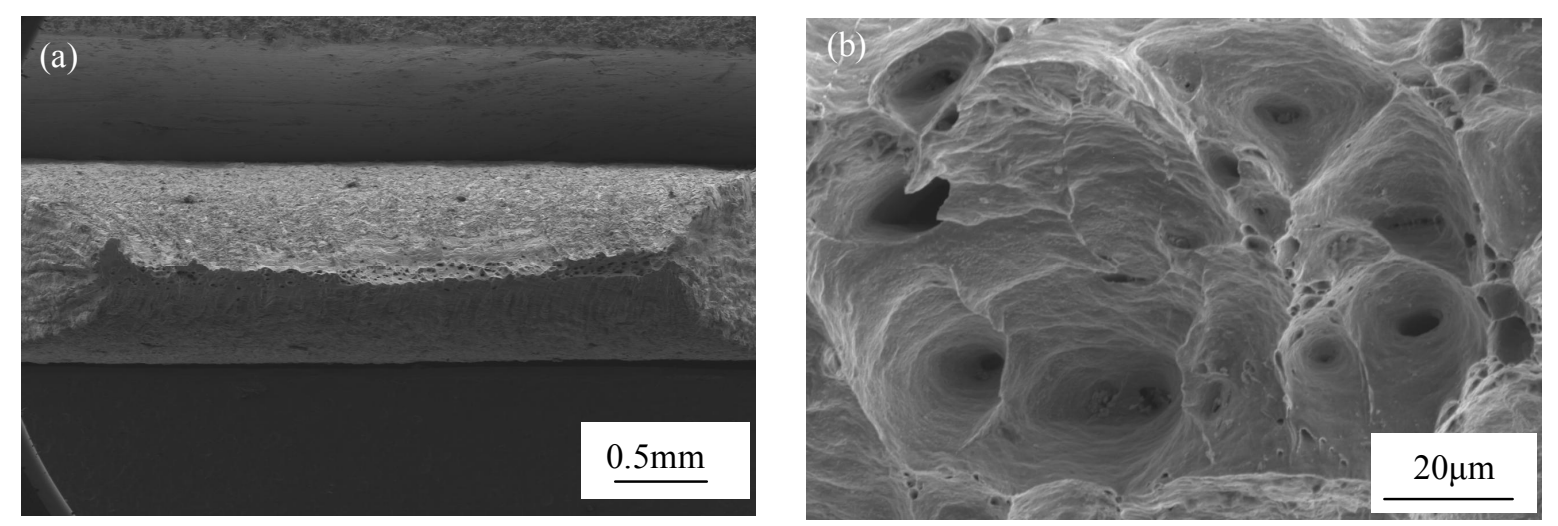

Fig. 7 Typical SEM fracture micrographs of 409M steel at $650^{\circ}$ Cand $60 \mathrm{MPa}$ after creep (a)low magnification; (b) high magnification

\section{Conclusions}

(1) A brief primary creep stage is characterized under the present test conditions. The steady-state creep rate increases and the rupture time decreases with an increase in the applied stress. 
(2) The steady-state creep rate can be described by the creep constitutive equation with the creep stress exponent $\mathrm{n}$ of 2.34 , which indicates a creep mechanism involving the grain boundary sliding.

(3) The creep rupture data show an excellent agreement with the Monkman-Grant relationship, and the smaller Monkman-Grant ductility indicates that the tertiary creep dominates the rupture strain of the $409 \mathrm{M}$ steel.

(4) The SEM micrographs of creep fracture surface reveal that the creep fracture mode for the 409M steel belongs to transgranular ductile fracture.

\section{Acknowledgments}

This work is financially supported by the National Natural Science Foundation of China (No.51134010).

\section{References}

[1] Jian Han, Huijun Li, Haigang Xu: Mater. Des., Vol. 58(2014), p.518

[2] G.M. Sim, J.C. Ahn, S.C. Hong: Mater. Sci. Eng. ,A, Vol. 396 (1-2)(2005), p.159

[3] N. Fujita, K. Ohmura and A. Yamamoto: Mater. Sci. Eng., A, Vol. 351(1-2) (2003), p.272

[4] J.K. Kim, Y.H. Kim, S.H. Uhm, J.S. Lee and K.Y. Kim: Corros. Sci., Vol. 51(11) (2009), p.2716

[5] T.K. Ha, H. Jeong and H.J. Sung: J. Mater. Process. Technol., Vol. 187-188(2007), p.555

[6] Xin Zhang, Lijun Fan, Yulai Xu, Jun Li, Xueshan Xiao and Laizhu Jiang: Mater. Des., Vol. 65(2015), p. 682

[7]A.K. Lakshminarayanan, V. Balasubramanian: J. Iron Steel Res., Int., Vol.19 (1) (2012), p.72

[8] Yating Shan, Xinghong Luo, Xiaoqiang Hu and Shi Liu: J. Mater. Sci. Technol., Vol. 27(4)(2011), p.352

[9] Haitao Yan, Hongyun Bi, Xin Li and Zhou Xu: Mater. Charact., Vol. 59(12) (2008), p.1741

[10] Haitao Yan, Hongyun Bi, Li Xin and Zhou Xu: Mater. Charact., Vol. 60(3) (2009), p.204

[11] H. Osman, A. Borhana and M. Tamin: J. Mater. Eng. Perform., Vol. 23(8) (2014), p.2858

[12] Lixin Wang, Changjiang Song, Fengmei Sun, Lijuan Li and Qijie Zhai: Mater. Des., Vol. 30(1) (2009), p.49

[13] J. Froitzheim, G.H. Meier, L. Niewolak: J. Power Sources, Vol. 178(2008), p.163

[14] Tianlong Liu, Lijia Chen, Hongyun Bi and Xin Che: Acta Metall. Sin. (Engl. Lett.), Vol. 27(3) (2014), p.452

[15] C.C. Silva, J.P. Farias, H.C. Miranda, R.F. Guimaraes, J.W. Menezes and M.A.M. Neto: Materials Characterization, Vol. 59(5) (2008), p. 528

[16] Jian Han, Huijun Li, Zhixiong Zhu, Laizhu Jiang, Haigang Xu and Li Ma: Mater. Sci. Eng., A, Vol. 616(2014), p.20

[17] Y.T. Chiu, C.K. Lin and J. C. Wu: J. Power Sources, Vol. 196(2011), p. 2005

[18] N.E. Dowling, Mechanical Behavior of Materials, 3rd ed., New Jersey, 2007

[19]C. Phaniraj, B.K. Choudhary, K.B.S. Rao and B.Raj: Scripta Mater., Vol. 48(9) (2003), p.1313 